\title{
Bending a tree while it is young: Getting pain management training on the academic map
}

\author{
Daniel. S. Engeler, MD \\ Department of Urology, Cantonal Hospital St. Gallen, St. Gallen, Switzerland
}

See related article on page 456.

Cite as: Can Urol Assoc J 2013;7(11-12):462. htrp://dx.doi.org/10.5489/cuaj.1809

Published online December 5, 2013.

$\mathrm{T}$ he authors of the paper have to be congratulated for their idea to focus on the important issue of training in management of acute and chronic pain. Probably most urologists and other clinical specialists around the world would agree that structured training in the management of pain during medical school or residency draws only very limited attention.

Guidelines for general pain management are available from some pain societies, but also urology-specific guidelines with regard to pain exist. ${ }^{1,2}$ But guidelines only accomplish their purpose if they are implemented in daily practice, and most importantly transferred into medical education programs.

The management of patients with pain, especially in the case of chronic pain, is often a difficult task. Many hospitals in industrialized countries now have acute pain management and palliative care services, but these are not available to everybody at all times. Therefore, the individual treating physician often is the first and most important part of the team and must understand different aspects of treatment. In the optimal case for the management of chronic pain, a multidisciplinary team should care for the patient, focussing on all aspects of pain, including psychological and functional consequences using an integrative approach. ${ }^{3}$ As with other difficult medical treatments, opioid use for pain is criticized for its inappropriate application. It is important to know how and when to use opioids; however, it is equally crucial to know when they should be avoided. Guidance on all of this is important and should be part of structured training.

An experiential or "learning by doing" approach for most of pain management issues is insufficient. If treatment selection is based on habits rather than evidence, optimal management will often be lacking.
Pace and colleagues demonstrate that the importance of acute and especially chronic pain management for medical training is underestimated by responsible authorities. ${ }^{4}$ Less than a quarter of the respondents received formal training during their residency program. Managing pain turns out to be just another "thing to do" and not a main focus of patient care. Consequently, proper management of patients in pain does not attract the attention needed, and inappropriate choice of treatment may follow.

As a consequence of this paper, one should argue that the discrepancy between the lack of formal training and the perceived need for more structured teaching in pain management should lead educational program directors to close this gap by improving curricula. A tree must be bent while it is young - an improvement of patient care for pain must start early during medical training.

Competing interests: Dr. Engeler declares no competing financial or personal interests.

\section{References}

1. Engeler D, Baranowski AP, Borovicka J, et al.; members of the European Association of Urology (EAU) Guidelines Office. Guidelines on Chronic Pelvic Pain. In: EAU Guidelines, edition presented at the 28th EAU Annual Congress, Milan; 2013. http://www.uroweb.org/gls/pdf/25_Chronic_Pelvic_Pain_LR.pdf. Accessed November 14, 2013.

2. Paez Borda A, Charnay-Sonnek F, Fonteyne V, et al.; members of the European Association of Urology (EAU) Guidelines Office. Guidelines on Chronic Pelvic Pain. In: EAU Guidelines, edition presented at the 28th EAU Annual Congress, Milan; 2013. http://www.uroweb.org/gls/pdf/24_Pain_Management_LR.pdf. Accessed November 14, 2013.

3. Engeler DS, Baranowski AP, Dinis-Oliveira P, et al. The 2013 EAU Guidelines on Chronic Pelvic Pain: Is Management of Chronic Pelvic Pain a Habit, a Philosophy, or a Science? 10 Years of Development. Eur Urol 2013;64;431-9. http://dx.doi.org/10.1016/i.eururo.2013.04.035

4. Pace J, Jaeger $M$, Nickel JC, et al. Pain management in urology training: A national survey of senior residents. Can Urol Assoc J 2013;7:456-61. http://dx.doi.org/10.5489/cuaj.1562

Correspondence: Dr. Daniel. S. Engeler, Department of Urology, St Gallen Cantonal Hospital, Rorschacher Strasse 95, 9007 St Gallen, Switzerland; daniel.engeler@kssg.ch 